\title{
COOLING OF A TRUCK CABIN BY VAPOUR ABSORPTION REFRIGERATION SYSTEM USING ENGINE EXHAUST
}

\author{
Shekhar D. Thakre ${ }^{1}$, Prateek D. Malwe ${ }^{2}$, Rupesh L. Raut ${ }^{3}$, Amol A. Gawali ${ }^{4}$ \\ ${ }^{1}$ Student, Department of Mechanical Engineering, Walchand College of Engineering, Sangli, Maharashtra, India \\ ${ }^{2}$ Student, Department of Mechanical Engineering, Walchand College of Engineering, Sangli, Maharashtra, India \\ ${ }^{3}$ Student, Department of Mechanical Engineering, Walchand College of Engineering, Sangli, Maharashtra, India \\ ${ }^{4}$ Student, Department of Mechanical Engineering, Walchand College of Engineering, Sangli, Maharashtra, India
}

\begin{abstract}
Air conditioning cabin of a transport truck is a new concept in India and has not been addressed. But in summer, the temperature in some parts of India is very high and results in unbearable cabin temperatures. In such conditions, an air cooled cabin for transport truck is a necessity. It is observed that much work has not been done in the field of cabin cooling of transport truck. The available options in heat generated cooling have been critically reviewed. The vapour absorption refrigeration cycle is found to be suitable for automobile air cooling especially for transport trucks. The heat potential in the exhaust has been analyzed and found to be sufficient enough for powering the proposed air conditioning system. The significance of the work is that it will provide space cooling for the truck driver and thereby enhances his performance and efficiency without affecting performance of the engine essentially the fuel economy. Further the vapor absorption cycle use non CFC refrigerant and thereby have little effect on environment. The present work is focused towards the design and development of an air cooling system for the cabin of truck using waste heat from exhaust. This document gives information about how much important is waste heat and using this we can develop a refrigerant system without taking input from battery, also design is developed based on vapour absorption refrigeration system which demands for future. In this article, we design different parts of the system and there basics behind this. Also, we study thermodynamic analysis of ammonia vapour absorption refrigeration system. From this we can concluded that the power required is less as compare with vapour compression refrigeration system and also study advantages over this.
\end{abstract}

Keywords: Vapour absorption refrigeration system, COP, Thermal conductivity, Generator, Ammonia, Absorber.

\section{INTRODUCTION}

In India road transport is a major mode of transport for goods over large distances. The atmospheric temperature in some parts of India touches $45^{\circ} \mathrm{C}$.In such condition studies shows that the temperature inside the cabin of a transport truck even exceeds $55^{\circ} \mathrm{C}$ (Alam, 2006) [1]. The operation in such hot condition for the truck driver is extremely difficult. Further this extreme heat reduces the working efficiency of the drivers and delays the transport duration over the road. The delay further affects the economy, which is unacceptable. So some measures have to be taken to reduce the temperature inside the cabin of the truck and to provide comfort to the driver. Considering present energy crises all over the world, it is very much necessary to explore new technology and potential to satisfy the need of society. At the same time the efficient management of the production and energy conservation is also equally important. In case of truck large amount of heat as input around $25 \%$ of the total heat supplied is going away with exhaust gases at very high temperature and around $25 \%$ is going away with cooling water. So if this waste heat can be utilized for powering an air conditioning system it will be economical and the fuel energy can be used effectively. Considering all the above factors different alternatives have been studied and the vapor absorption system is found to be the most promising alternative. The paper deals with the preliminary design of Ammonia water vapor absorption refrigeration system and a simulation model has been developed for both the systems to predict the performance of the systems, designed for given operating conditions, under various off-design operating conditions. The significance of the work is that it will provide space cooling for the truck driver and thereby enhances his performance and efficiency without affecting performance of the engine essentially the fuel economy. Further the vapor absorption cycle use non CFC refrigerant and thereby have little effect on environment.

\subsection{Literature Survey}

To provide air cooling for the driver of a truck is never given importance in India, the basic reason is the use of available methods of air cooling affects the fuel consumption and the initial cost of the truck. For automobile air conditioning normally vapour compression refrigeration cycle is used. The cycle run on engine power and consumes around $10 \%$ of the total power produced by the engine and thereby increases the fuel consumption shown by Lambart and Jones, 2006 [2]. Till date, 1 TR VAR system has been neither built practically nor simulated for analyzing the performance of the system because of its low COP (Jakob et al, 2007) [3]. Due to this reason, no information is available regarding the performance of 1 TR VAR system. The work carried out in this project holds significance not only because it shows the practicability of fabricating a 1 TR VAR system for providing cabin cooling of truck by using 
engine exhaust but also it makes available the information about the performance of such a system under different operating conditions.

\section{VAPOUR ABSORPTION CYCLE}

Vapour absorption cycle is a refrigeration cycle (VAR) which produces refrigerating effect by using heat as input and a very little mechanical work is required to operate VAR cycle (figure. 1). The working fluid is usually an Ammonia water or Lithium bromide solution in water. French scientist Ferdinand Carre developed the first absorption refrigeration machine in 1816. Practically the VAR cycle were first developed as Ammonia water system around the start of the $20^{\text {th }}$ century with the Lithium Bromide system around. Since the 1950's (Manrique, 1991) [4], A historic perspective shows that air conditioning of building has been practiced from about 120 years and the first systems were heat driven absorption system (Wicks, 1989) [5]. Vapour absorption cycle could not become popular because of its low Coefficient of Performance (COP). Some efforts have been concentrated towards the improvement in COP of the VAR cycle. Jakob (2007) [2] has presented an experimental investigation work in which average COP of 0.3 at heating inlet temperature of $125^{\circ} \mathrm{C}$ was obtained. Some theoretical investigation claims COP of the order of 0.7 to 1 . The COP is still well below that of $\mathrm{VC}$ cycle. For this reason vapour absorption cycle is mainly used in systems where heat energy is available free of cost like solar energy or waste energy such as exhaust from automobile engines. Since the end of 1970, many kinds of solar air conditioning systems has been developed with technical success. In most of the solar cooling systems hot water driven single stage lithium bromide absorption chiller were commonly used. Relying on the success of the above systems, an integrated solar cooling and heating systems was constructed for cooling capacity of $100 \mathrm{~kW}$ successfully. (Sumathy et al, 2001) [6], (Bell et al, 1996) [7]. Some efforts have been made to integrate absorption and vapour compression systems. Results show that some efforts were successful to achieve a good value of COP driven by solar energy (Riffat and Shankland, 1993) [8]. Salim Munther (2001) [9] in his theoretical study and analysis has claimed that exhaust heat energy is capable of powering and producing cooling effect upto 1.4 tons of refrigeration using VAC. A broadband prototype of an absorption system for truck refrigeration for the transported food stuff by using heat from the exhaust gases was designed, built and tested. Measured C.O.P. values of the less optimized single stage ammonia water absorption cycle varied between 23 to $30 \%$ (Koehler, 1997) [10]. A procedure has been presented for the thermodynamic analysis of a combined naturally aspirated diesel engine and absorption refrigeration machine. (Mostafavi and Agnew 1997) [11]. Venkatesh and Praveen (2005) [12] have suggested that it is possible to drive a vapour absorption refrigeration system for air conditioning of a car using the exhaust gases from the engine. A case study for "Honda city Exi" has been presented in which a cooling potential of 2.5 $\mathrm{T}$ has been justified. A dynamic simulation of an ammonia water absorption system has been presented for $10.5 \mathrm{~kW}$ absorption systems (Kim and Park, 2007) [13]. An optimization analysis is presented for estimating the proper size of absorption type automotive air conditioning system that use waste exhaust heat as input.

\subsection{Ammonia/Water Absorption Cycle}

An Absorption Cycle can be viewed as a mechanical vaporcompression cycle, with the compressor replaced by a generator, absorber and liquid pump. Absorption cycles produce cooling and/or heating with thermal input and minimal electric input, by using heat and mass exchangers, pumps and valves. The absorption cycle is based on the principle that absorbing ammonia in water causes the vapor pressure to decrease.

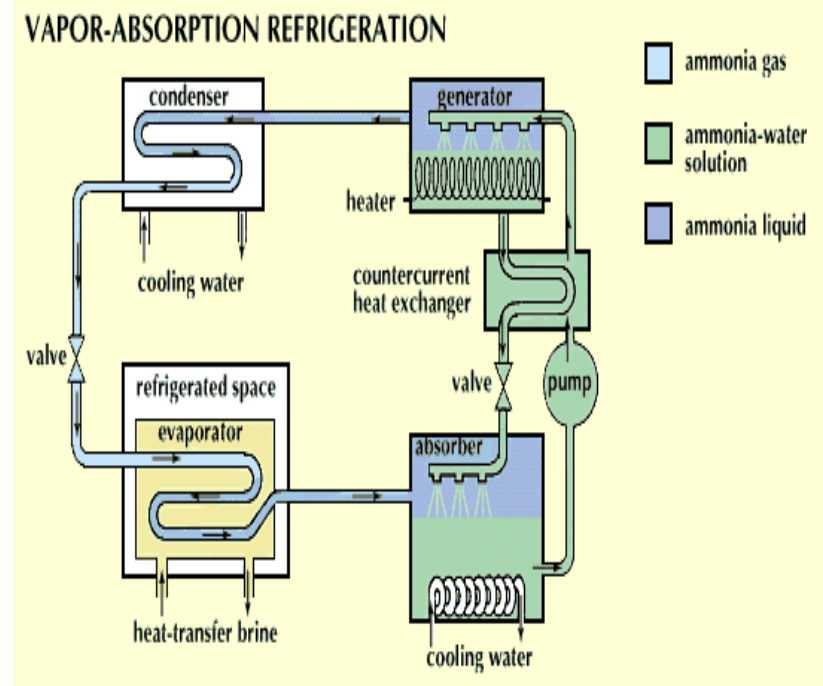

Fig -1: Ammonia/water absorption cycle

The basic operation of an ammonia-water absorption cycle is as follows. Heat is applied to the generator, which contains a solution of ammonia water, rich in ammonia. The heat causes high pressure ammonia vapor to desorb the solution. Heat can either be from combustion of a fuel such as clean-burning natural gas, or waste heat from engine exhaust, other industrial processes, solar heat, or any other heat source. The high pressure ammonia vapor flows to a condenser, typically cooled by outdoor air. The ammonia vapor condenses into a high pressure liquid, releasing heat which can be used for product heat, such as space heating. The high pressure ammonia liquid goes through a restriction, to the low pressure side of the cycle. This liquid, at low pressures, boils or evaporates in the evaporator. This provides the cooling or refrigeration product. The low pressure vapor flows to the absorber, which contains a water-rich solution obtained from the generator. This solution absorbs the ammonia while releasing the heat of absorption. This heat can be used as product heat or for internal heat recovery in other parts of the cycle, thus unloading the burner and increasing cycle efficiency. The solution in the absorber, now once again rich in ammonia, is pumped to the generator, where it is ready to repeat the cycle. 


\subsection{Design Considerations for Ammonia/Water}

System

\subsubsection{Properties of Ammonia and Safety Concerns}

Ammonia is a naturally occurring substance that is produced and used in large quantities (in the US alone 20 million tons per year IPCS, ammonia health and safety guide, publ. World health org. Programmed on chemical safety, Geneva, 1990) for agriculture as fertilizer and as the source material for fibers, plastics and explosive .consequently it is shipped in large quantities by rail and ship. Ammonia is also used as a cleaning and de - scaling agent and food additives. Ammonia is a colorless gas of flow density at room temperature with a pungent smell. It has relative molecular mass of 17.03 and is lighter than air and atmospheric conditions. It can be stored and transported as a liquid under a pressure of $1 \mathrm{MPa} 25^{\circ} \mathrm{c}$. The critical point of ammonia is at $132.3^{\circ} \mathrm{c}$ and $11.3 \mathrm{MPa}$. The critical density is $235 \mathrm{~kg} / \mathrm{m}^{3}$ Since ammonia is highly soluble in water generating $\mathrm{NH}_{4}{ }^{+}$ and $\mathrm{OH}^{-}$ions, it reacts very quickly with mucus membranes. However, it is not absorbed through the skin. It can be smelled by humans in concentration of very few ppms at about $50 \mathrm{ppm}$, the odor is almost unbearable. This is also the concentration range $(25 \mathrm{ppm})$ to which long-term exposure is limited from an occupational health point of view, (IPCS, 1990,ammonia health and safety, Geneva )at high dosages ammonia exposure can be lethal. Ammonia is flammable and explosive in the range of 16 to 25 vol. \% (IPCS, 1990, ammonia health and safety, guide, publ. World health org. Programmed on chemical safety, Geneva) in air. The strong odor of ammonia can be seen as an asset. It is self alarming. Even very small leak in system are easily noticed and therefore a significant incentive exists for early repairs and consistent maintenance. One method of leak detection is to use wet indicator paper, which will quickly change its color once it is exposed to air with a few ppm of ammonia content. However, traditional leak detection devices such soap (or bubble) solutions do not work since the ammonia is dissolved in the water without creating bubbles.

\subsubsection{Water Content of the Refrigerant Vapour}

The first important difference is the vapor pressure of ammonia / water mixtures compared to that of water/lithium bromide. Here, ammonia is the refrigerant. The normal boiling point is the $-33.35^{\circ} \mathrm{c}$. And therefore the pressure of such systems at the temperatures normally encountered in air-conditioning and refrigeration applications is relatively high. The pressure is comparable to vapor compression systems that utilize R22 as the refrigerant. The high vapor pressure leads to rather small pipe diameters, and relatively compact heat exchange as compare to Water/LiBr. A second important difference is that the absorbent (water) has a vapor pressure that is not negligible relative to that of ammonia. As a consequence, the vapor generated in the desorber contains a certain amount of water. (The mass fraction depends on the mass fraction of the liquid mixture in the desorber, the temperature and the desorber design. Any water contained in the desorber vapor is detrimental to the performance of the system). The water will pass with the vapor into the condenser and then into the evaporator where the water tends to accumulate if a poor boiler design is used. The vapor leaving the evaporator is rich in ammonia. Although it still contains some water, the ammonia mass fraction of the vapor is considerably higher than that of the vapor leaving the desorber. Thus water will remain in the evaporator. If no other measures are taken the evaporator temperature has to be increased considerably to evaporate the remaining water-rich solution.

An accumulation of water will lead to decrease in evaporator pressure which in turn will affect the absorber conditions. As the water accumulates in the evaporator the pressure drops for a constant evaporator temp which is fixed by the application. The absorber has either to be cooled to a lower temp or the mass fraction of the solution has to change to lower ammonia content. Assuming that the desorber temps do not change, the condenser temp must drop which is usually prohibited by the cooling water temp available to the condenser. a consequence the high pressure level has to be raised and the desorber temp will increase as well. As the water continue to accumulate in the evaporator the operating conditions of the entire system drift and operation at design conditions is not possible. One way of preventing excessive water accumulation is to drain it periodically into the absorber. However this method represents loss of efficiency in 2 ways. First the water was evaporated in the desorber requiring desorber heat input, but it does not evaporate in the evaporator; thus it does not provide to the cooling capacity. Second it contains a considerable amount of ammonia that is retained as liquid, amplifying this effect.

\subsubsection{Material Consideration for Ammonia /Water}

\section{System}

Ammonia is a very good solvent for copper. Thus the use of any copper or copper-containing material is impossible. Experience in the laboratory indicates that even chromiumplated brass parts are susceptible to ammonia corrosion. The most common material for the construction of ammonia/water systems is steel or stainless steel. When steel is the material of choice, corrosion inhibitors are required for most applications. These are salts that are added in small quantities ( $1 \%$ by weigh or so.).They form a protective oxide layer on the metal surface so that there is no direct contact with the working fluid. The influence of these salts on the thermodynamic properties of the working fluid is usually neglected. Traditionally, the corrosion inhibitors are salts that contain heavy metals. These are being banned by the U.S., Environmental Protection Agency and manufacturers find themselves needing to develop new, environmentally acceptable replacements. The thermal conductivity of steel is about one tenth of that of copper. Thus the heat transfer resistance of the wall material may no longer be negligible. Since ammonia has relatively high vapor pressure, the machines are not as susceptible to performance degradation due to presence of no condensable gases as water/lithium bromide systems. However it is 
nevertheless good practice to keep all non condensable out of the system.

\section{THERMODYNAMIC DESIGN}

To perform a thermodynamic analysis for an absorption refrigeration system, the mass and energy balance equations were applied to each component in the absorption system A standard set of condition for $\mathrm{Li}-\mathrm{Br}$ and ammonia-water system is referred. With reference to the figure and applying the heat balance the operating conditions are obtained for a 1TR VAR system. The limiting conditions are decided. Engine cooling water assumed to be at $95^{\circ} \mathrm{C}$, atmospheric air at $45^{\circ} \mathrm{C}$ and exhaust gas temperature at $200{ }^{\circ} \mathrm{C}$. Considering the temperature of evaporator and condenser as the saturation temperature of the refrigerant used, the pressure in the evaporator and condenser are decided.

\subsection{Heat Available From Engine}

Actual heat available from the engine is calculated as follows;

$$
\mathrm{FP}=\mathrm{m}_{\mathrm{f}} \times \mathrm{CV}
$$

Where, $\quad \mathrm{m}_{\mathrm{f}}=$ fuel mass flow rate

$\mathrm{CV}=$ calorific value of the fuel $42000 \mathrm{~kJ} / \mathrm{kg}$

Taking 12 liter per hour fuel consumption for a 150 BHP engine. The available heat rejected by the cooling system can be expressed as:

$$
\begin{gathered}
\mathrm{Q}_{\text {rejected }}=0.3 \times \mathrm{m}_{\mathrm{f}} \times \mathrm{CV} \\
\mathrm{Q}_{\text {rejected }}=34 \mathrm{~kW}
\end{gathered}
$$

\subsection{Load Calculation}

The cooling load required for cabin cooling is calculated by using standard method of load calculation. The various factors of heat load like solar radiation (roofs, walls, glasses) normal heat gain through glass, normal heat gain through wall, air infiltration, number of persons in cabin sensible heat load, Latent heat load can be calculated using ASHRAE Hand book. (Alam, 2006) [1], (Venkatesh and Pravin 2005) [12].

Table -1: System observations

\begin{tabular}{|l|l|}
\hline Parameter & Value \\
\hline Cabin Dimensions & $(2 \times 1.75 \times 1.5) \mathrm{m}^{3}$ \\
\hline Ambient Temperature & $45^{0} \mathrm{C}$ \\
\hline Cabin Temperature without cooling & $55^{0} \mathrm{C}$ \\
\hline Design temperature of cabin & $30^{0} \mathrm{C}$ \\
\hline Solar radiation (roof, walls glasses) & $300 \mathrm{~kJ} / \mathrm{hr}$ \\
\hline Normal heat gain through glasses & $1200 \mathrm{~kJ} / \mathrm{hr}$ \\
\hline Normal Heat gain through walls & $4300 \mathrm{~kJ} / \mathrm{hr}$ \\
\hline Air leakage & $1000 \mathrm{~kJ} / \mathrm{hr}$ \\
\hline Passenger including driver & $1200 \mathrm{~kJ} / \mathrm{hr}$ \\
\hline Heat radiated from engine & $2000 \mathrm{~kJ} / \mathrm{hr}$ \\
\hline Total & $\mathbf{1 0 0 0 0} \mathbf{~ k J / h r}$ \\
\hline
\end{tabular}

Total heat load to the truck Cabin is $2.8 \mathrm{~kW}$ therefore a cooling system of 1 TR $(3.5 \mathrm{~kW})$ should be sufficient.

A transport truck of $150 \mathrm{~B} \mathrm{H} \mathrm{P}$ is considered and the heat available in exhaust is $50 \mathrm{~kW}$ and cooling water $=45 \mathrm{~kW}$ (Engine running at $50 \%$ of maximum power.)

Heat required for 1 TR with COP $0.2=17.5 \mathrm{~kW}$.

It is very clear that available heat potential is sufficient and engine cooling water can run the proposed cooling system.

\section{THERMODYNAMIC ANALYSIS}

To perform a thermodynamic analysis for an absorption refrigeration system, the mass and energy balance equations were applied to each component in the absorption system

A standard set of condition for ammonia-water system is referred. With reference to the figure and applying the heat balance the operating conditions are obtained for a 1TR VAR system. The limiting conditions are decided. Engine cooling water assumed to be at $95^{\circ} \mathrm{C}$, atmospheric air at $45^{\circ} \mathrm{C}$ and exhaust gas temperature at $200{ }^{\circ} \mathrm{C}$. Considering the temperature of evaporator and condenser as the saturation temperature of the refrigerant used, the pressure in the evaporator and condenser are decided. The other pressures and temperature are decided based on data from references and practical conditions. Values of enthalpy are obtained from Steam Table \& Enthalpy Concentration Diagram for $\mathrm{Li}-\mathrm{Br}$ system and for Ammonia/water system Enthalpy Concentration Diagram \& Pressure Temperature Diagram are referred.

The configuration of a single effect absorption system is shown in figure 2 below. The system is to operate under following conditions:

Table -2: System observations

\begin{tabular}{|l|l|l|}
\hline Parameter & Symbol & Value \\
\hline Refrigeration capacity & $\mathrm{Q}_{\mathrm{e}}$ & $3.5 \mathrm{~kW}$ \\
\hline Evaporator temperature & $\mathrm{T}_{\mathrm{e}}$ & $5{ }^{\circ} \mathrm{C}$ \\
\hline Condenser temperature & $\mathrm{T}_{\mathrm{c}}$ & $55^{\circ} \mathrm{C}$ \\
\hline Generator temperature & $\mathrm{T}_{2}$ & $200{ }^{\circ} \mathrm{C}$ \\
\hline Heat Exchanger Effectiveness & $€$ & 0.70 \\
\hline Generator and condenser & $\mathrm{P}_{2}$ & $20 \mathrm{bar}$ \\
\hline Absorber and evaporator & $\mathrm{P}_{1}$ & $5 \mathrm{bar}$ \\
\hline Weak solution & $\mathrm{X}_{1}$ & 0.368 \\
\hline Strong solution & $\mathrm{X}_{2}$ & 0.268 \\
\hline
\end{tabular}




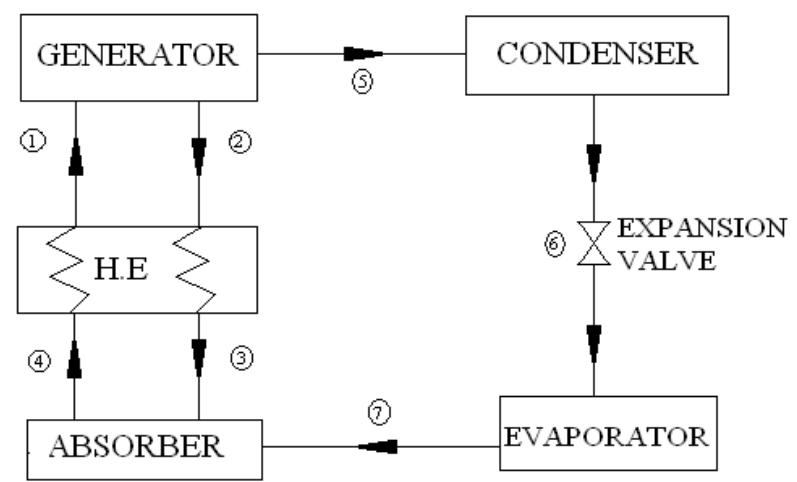

AMMONLA WATER ABSORPTION COOLING SYSTEM

Fig -2: Block diagram of ammonia vapour absorption system

In the figure above state points represent the conditions as stated below:

1. Strong solution entering the generator

$\left(\mathrm{X}_{1}=0.368\right)$

2. Weak solution leaving the generator

$\left(\mathrm{X}_{2}=0.268, \mathrm{~T}_{2}=200{ }^{\circ} \mathrm{C}\right)$

3 . Weak solution leaving the heat exchanger

$\left(\mathrm{X}_{3}=0.268\right)$

4. Weak solution entering the absorber

$\left(\mathrm{X}_{3}=0.268\right)$

5. Strong solution entering the heat exchanger

$\left(\mathrm{X}_{4}=0.368, \mathrm{~T}_{4}=55^{\circ} \mathrm{C}\right)$

6. Strong solution leaving the absorber

$\left(\mathrm{X}_{4}=0.368, \mathrm{~T}_{4}=55^{\circ} \mathrm{C}\right)$

7. Refrigerant vapour leaving the generator

(Superheated to $200{ }^{\circ} \mathrm{C}$ at the pressure of 20 bar $\mathrm{T}_{5}=200{ }^{\circ} \mathrm{C}$, $\mathrm{P}_{5}=20$ bar)

8. Refrigerant liquid leaving the condenser

(Saturated at $55{ }^{\circ} \mathrm{C}, \mathrm{T}_{6}=55^{\circ} \mathrm{C}, \mathrm{P}_{6}=20$ bar)

9. Refrigerant vapour entering the absorber

(Saturated at $5{ }^{\circ} \mathrm{C}, \mathrm{T}_{7}=5{ }^{\circ} \mathrm{C}, \mathrm{P}_{7}=5$ bar)

10. Refrigerant liquid entering the evaporator

(Saturated at $55{ }^{\circ} \mathrm{C}, \mathrm{T}_{6}=55^{\circ} \mathrm{C}, \mathrm{P}_{6}=20$ bar)

Heat and mass balance is applied to each component to determine the heat transfer and mass flow rates.

Table -3: Properties of absorbent and refrigerant at various state points

\begin{tabular}{|l|l|l|l|l|}
\hline State & $\mathrm{h}(\mathrm{kJ} / \mathrm{kg})$ & $\mathrm{T}\left({ }^{\circ} \mathrm{C}\right)$ & $\mathrm{m}(\mathrm{kg} / \mathrm{hr})$ & $\mathrm{x}$ \\
\hline 1 & 478.1 & 158 & 92.88 & 0.368 \\
\hline 2 & 750 & 200 & 80.28 & 0.268 \\
\hline 3 & 260 & 98.5 & 80.28 & 0.268 \\
\hline 4 & 20 & 55 & 92.88 & 0.268 \\
\hline 5 & 1447.76 & 200 & 12.726 & 1 \\
\hline 6 & 290 & 55 & 12.726 & 1 \\
\hline 7 & 1280 & 5 & 12.726 & 1 \\
\hline
\end{tabular}

Table -4: Properties of absorbent and refrigerant at various state points for constant condenser and varying Generator temperature

\begin{tabular}{|l|l|l|l|l|}
\hline \multicolumn{5}{|l|}{ Taking $\mathrm{T}_{\mathrm{c}}=50{ }^{\circ} \mathrm{C}$ varying Generator temp } \\
\hline State & $\mathrm{h}(\mathrm{kJ} / \mathrm{kg})$ & $\mathrm{T}\left({ }^{\circ} \mathrm{C}\right)$ & $\mathrm{m}(\mathrm{kg} / \mathrm{sec})$ & $\mathrm{x}$ \\
\hline 1 & 518.8 & & 0.02409 & 0.368 \\
\hline 2 & 826.5 & 150 & 0.0208 & 0.268 \\
\hline 3 & 252 & 83.5 & 0.0208 & 0.268 \\
\hline 4 & 22.82 & 55 & 0.02409 & 0.268 \\
\hline 5 & 1588 & 150 & 0.003291 & 1 \\
\hline 6 & 210.6 & 55 & 0.003291 & 1 \\
\hline 7 & 1274 & 5 & 0.003291 & 1 \\
\hline $\mathrm{Q}_{\mathrm{e}}$ & 3.5 & & & \\
\hline $\mathrm{Q}_{\mathrm{g}}$ & 9.919 & $\mathrm{COP}$ & 0.352858 & \\
\hline
\end{tabular}

\section{RESULTS \& DISCUSSIONS}

Brief summary of the parameters required for plotting the graph to determine the characteristics from the plot. The performance of system under operating conditions has been studied by varying the generator and condenser temperatures. The results of generator and condenser temperature variation on COP by different components of the system are presented in form of several graphs as shown.

Table -5: COP of system for different generator and condenser temperature

\begin{tabular}{|l|l|l|l|l|l|l|}
\hline \multirow{2}{*}{$\begin{array}{l}\text { Generator } \\
\text { Temperature }\end{array}$} & \multicolumn{6}{|l|}{ Condenser temperature } \\
\cline { 2 - 7 } & 50 & 54 & 58 & 62 & 66 & 70 \\
\hline 150 & 0.352 & 0.347 & 0.341 & 0.336 & 0.330 & 0.324 \\
\hline 160 & 0.349 & 0.344 & 0.338 & 0.333 & 0.327 & 0.322 \\
\hline 170 & 0.346 & 0.341 & 0.335 & 0.330 & 0.324 & 0.319 \\
\hline 180 & 0.343 & 0.338 & 0.333 & 0.327 & 0.322 & 0.316 \\
\hline 190 & 0.341 & 0.335 & 0.330 & 0.324 & 0.319 & 0.314 \\
\hline 200 & 0.338 & 0.332 & 0.327 & 0.321 & 0.316 & 0.311 \\
\hline
\end{tabular}

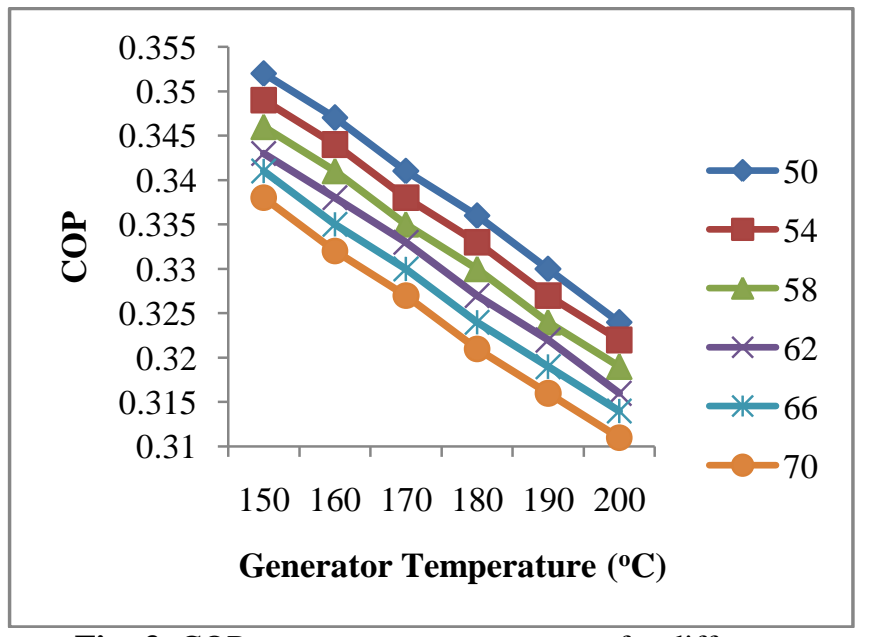

Fig -3: COP vs. generator temperature for different condenser temperature 
Table -6: Generator load of system for different generator and condenser temperature

\begin{tabular}{|l|l|l|l|l|l|l|}
\hline \multirow{2}{*}{$\begin{array}{l}\text { Generator } \\
\text { Temperature }\end{array}$} & \multicolumn{6}{|l|}{ Condenser temperature } \\
\cline { 2 - 7 } & 50 & 54 & 58 & 62 & 66 & 70 \\
\hline 150 & 9.919 & 10.08 & 10.24 & 10.41 & 10.58 & 10.77 \\
\hline 160 & 10.01 & 10.17 & 10.33 & 10.5 & 10.68 & 10.86 \\
\hline 170 & 10.09 & 10.25 & 10.42 & 10.59 & 10.77 & 10.95 \\
\hline 180 & 10.18 & 10.34 & 10.51 & 10.68 & 10.86 & 11.05 \\
\hline 190 & 10.26 & 10.43 & 10.6 & 10.77 & 10.95 & 11.14 \\
\hline 200 & 10.35 & 10.52 & 10.69 & 10.87 & 11.05 & 11.24 \\
\hline
\end{tabular}

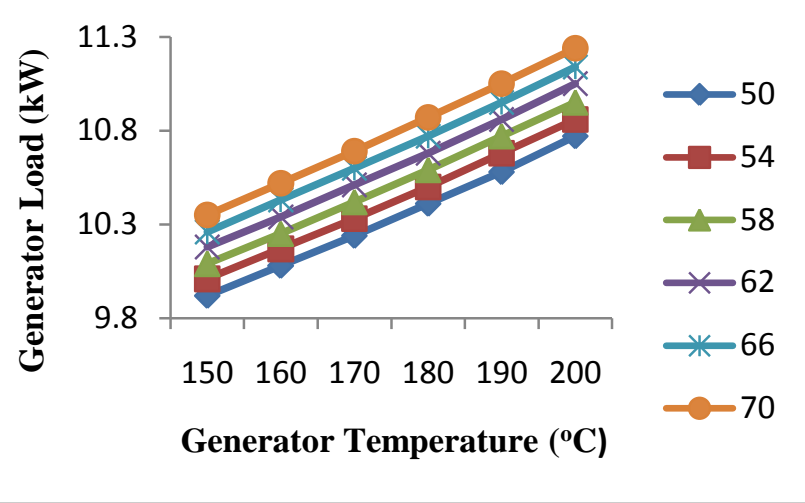

Fig -4: Generator load vs. generator temperature for different condenser temperature

1) The performance of a system under operating conditions has been studied by varying the generator and condenser temperatures. The results of generator and condenser temperature variation on COP of the system are presented in form of several graphs as shown.

2) The results indicate that the COP of single effect ammonia/water system varies from 0.3528 to 0.3113 , under different operating conditions being simulated. However this variation is marginal.

3) It may be noted that the COP decreases with the increase in generator temperature for given condenser temperature for the system. The COP of the system is very sensitive to change in condenser temperature and decreases rapidly with increase in condenser temperature. The COP of the system decreases with increase in generator temperature because evaporator load is constant (i.e. $3.5 \mathrm{~kW}$ as required for the cabin cooling of truck) and as the generator temperature increases, it increases the heat load of generator. The net effect is seen as decrease in value of COP.

4) From the graph plotted between COP \& heat load on generator for ammonia/water system, it can be seen that, under the various operating conditions being simulated, the maximum input to the generator as required in case of ammonia/water system is 11.24 $\mathrm{kW}$. From calculations it is known that the available energy rejected by cooling system of truck engine is $34 \mathrm{~kW}$. Thus the heat load on generator can be met very easily by using the engine exhaust for both the systems and is more than sufficient.

From above, it can be concluded that, for providing cabin cooling for truck using engine exhaust, vapour absorption systems can be used i.e. ammonia/water vapour absorption cycle.

\section{CONCLUSIONS}

From the results and discussions, it has been concluded that, for providing cabin cooling for truck using engine exhaust, the vapour absorption systems can be used i.e. ammonia/water vapour absorption cycle. The COP of ammonia/water system varies from 0.3528 to 0.3113 .

The heat load on the generator can be met very easily by using the engine exhaust for both the systems as available energy rejected by cooling system of truck engine is more than sufficient. Even with a minimum assumed COP of 0.2 , the required input to generator is $17.5 \mathrm{~kW}$, while waste heat available is $34 \mathrm{~kW}$.

Hence from the discussion, ammonia/ water vapour absorption system is suggested for the application. Though the COP of the system is less but since waste heat is given as input, it is not a matter of concern.

\section{ACKNOWLEDGEMENTS}

We would like to thank "BCUD, University of Pune" for giving us an opportunity to do the Research project under UOP funding. We are thankful to our project guides Prof. Dr. H. U. Tiwari and Prof. Dr. B. S. Gawali for guiding us in the right direction. Their evaluations, suggestions and encouragements have helped enormously towards completion of our project. Also, we would like to thank WCE, Sangli for financial support.

\section{REFERENCES}

[1] Alam S, 2006, "A Proposed model for Utilizing Exhaust Heat to run Automobile Air-conditioner", The $2^{\text {nd }}$ Joint International Conference on Sustainable Energy and Environment 21-23 November 2006, Bangkok, Thailand.

[2] Lambert M. A. and Jones B. J, 2006, "Automotive adsorption air conditioner powered by exhaust heat". Journal of Automobile Engineering. Vol. 220.

[3] Jakob. U, Eicker. U, Schneider. D and Teuber. A, 2007, "Experimental Investigation of Bubble Pump and System Performance for a Solar Driven $2.5 \mathrm{KW}$ Diffusion Absorption Cooling Machine" Heat Set 2007, Heat transfer in components and systems for energy technologies Chambery, France.

[4] Manrique J. A., 1991, "Thermal Performance of an Ammonia - Water Refrigeration System", International Comm. Heat Mass Transfer Vol. 18, pp. $779-789$.

[5] Wicks F, 1989, "Design and Benefits of a NonElectric Air Conditioner that Combines Compression 
and Absorption Cycle", SAE technical paper no. 899180.

[6] Sumathy. K, Huang. Z. C and Li. Z. F, 2002, "Solar Absorption Cooling with Low Grade Heat source - A Strategy of Development in South China", Elsevier Science Solar Energy Vol. 72, No 2, pp 155 - 165.

[7] Bell I. A, Daini A. J, Ali H. Abdel-Gayed R. G and Duckers L, 1996, "The Design of an Evaporator/Absorber and Thermodynamic analysis of a Vapour Absorption Chiller Driven by Solar Energy" WREC - 1996.

[8] Riffat S. B. and Shankland N, 1993, "Integration of Absorption and Vapor-Compression Systems", Elsevier, Applied Energy 46, 303-316.

[9] Salim M, 2001, "Technical Potential for Thermally Driven Mobile A/C Systems", SAE technical paper, no. 2001 - 01- 0297.

[10] Koehler. J, Tegethoff. W. J, Westphalen. D and Sonnekalb. M, 1997, "Absorption Refrigeration System for Mobile applications utilizing Exhaust Gases", Heat and Mass transfer 32(1997) 333-340.

[11] Mostafavi M and Agnew B, 1997, "Thermodynamic Analysis of Combined Diesel Engine and Absorption Refrigeration Unit - Naturally Aspired Engine with Precooling", Elsevier Science Applied Thermal Engineering Vol. 17. No 6. pp. 593-599.

[12] Venkatesan. J, Praveen. V. M, Bhargav. V. K and Moorthy. B. B, 2005, "Performance Improvement in Automotive Engines using Vapour Absorption Refrigeration System for Air Conditioning", SAE technical paper no. 2005-01-3466.

[13] Kim B and Park J, 2007, "Dynamic Simulation of a Single-effect ammonia-water absorption chiller", International Journal of Refrigeration Vol. - 30, 535-545.

\section{BIOGRAPHIES}

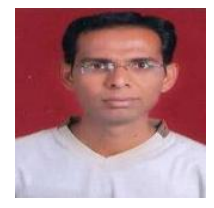

Shekhar Dinkar Thakre, M Tech (Thermal Engineering) Student, Department of Mechanical Engg, Walchand College of Engineering, Sangli, Maharashtra, India, shekhar10thakre@gmail.com

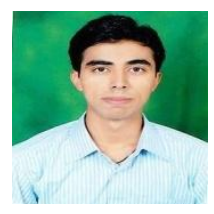

Prateek Deoman Malwe, M Tech (Thermal Engineering) Student, Department of Mechanical Engg, Walchand College of Engineering, Sangli, Maharashtra, India, prateek0519@gmail.com

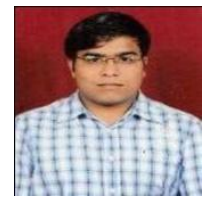

Rupesh Laldas Raut, M Tech (Thermal Engineering) Student, Department of Mechanical Engg, Walchand College of Engineering, Sangli, Maharashtra, India, rupeshraut992@gmail.com

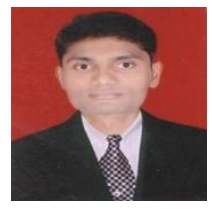

Amol Annasaheb Gawali, M Tech (Thermal Engineering) Student, Department of Mechanical Engg, Walchand College of Engineering, Sangli, Maharashtra, India, gawaliamol7@gmail.com 